\title{
City-to-City Cooperation in Environmental Infrastructure Installation
}

\author{
Injae Yu, Yoojung Jo, Saehyung Sohn, and Donyun Kim
}

\begin{abstract}
Nowadays, it is estimated that $70 \%$ of cities worldwide are engaged in various forms of city-to-city cooperation. Successful cities are able to establish a connection with the creative environment by different inter-city cooperatives and convergence. The construction of aversive facilities in the city which involves social issues such as the Nimby has found a solution in the cooperation between neighboring cities. In this study, the implications of city-to-city cooperation for the installation of aversive environmental infrastructure will be drawn out by case analysis of Korea. The focus of analysis is that the methods of city-to-city cooperation, the result of the cooperation and its effect. City-to-city cooperation regarding environmental infrastructure is expressed in the form of "sharing" facilities. Finally, in order to build a future of sustainable cities, it is wiser to focus on win-win development instead of focusing on each individual city's growth. Also, building the foundational infrastructure necessary for city development requires a change in public perception.
\end{abstract}

Index Terms-City-to-city cooperation, environmental facility, nimby phenomenon.

\section{INTRODUCTION}

\section{A. Background and Purpose}

Cities have emerged as centers of the society and economic systems of the country since the 20th century, with the world now reorganizing itself around the competitiveness of the city [1]. City-to-city cooperation [2] is now a critical issue in the 21 st century, the so-called 'era of the city'. Today about $70 \%$ of all cities have some kind of cooperative relationship with other cities [3]. Now the city has a rich potential for cross-linking, but in Asia, where demand and urbanization is growing [4], concrete cooperation strategies for sustainable cities are inadequate.

The policy needed to address climate change in particular stands out, for not only does one city's policy affect the region, they cannot solve the issue on its own nor can one give fault to it in particular as well [5]. Additionally, as its

Manuscript received December 31, 2014; revised May 4, 2015. This work is financially supported by Korea Minister of Ministry of Land, Infrastructure and Transport(MOLIT) as (U-City Manpower Development Program). And this study is funded by Ministry of Land, Infrastructure and Transport of Korean Government which conducts the core based technology development project for advancing U-City (Code 13AUDP-B070066-03).

Injae $\mathrm{Yu}$ and Yoojung Jo are with the Future City Convergence Engineering Department, Sung Kyun Kwan University, 440-746, 2066, Seobu-Ro, Jangan-Gu, Suwon, Gyeonggi-Do, Korea (e-mail: injaeyoo@naver.com, hcyoojung@gmail.com).

Saehyung Sohn and Donyun Kim are with the Architecture Department, Sung Kyun Kwan University, 440-746, 2066, Seobu-Ro, Jangan-Gu, Suwon, Gyeonggi-Do, Korea (e-mail: sohn6969@gmail.com,dnkim@skku.ac.kr). effects are not immediate but gradual, ongoing maintenance and management is required which also means the avoidance or neglect of such policies on part of a city also negatively affects the region [6]. City-to-city cooperation is an important factor not only in the development and maintenance of such environmental policies, but also in how a city utilizes its space, how it connects its houses and streets, and on a larger scale how a city interacts with its neighbor and the world at large.

City-to-city cooperation leads to a shared purpose and vision, encourages a joint effort to create value, with the cooperating cities eventually sharing the created value. Successful cities are able to establish a connection with the creative environment by different inter-city cooperatives and convergence. This is not limited to large cities, but can also be seen expressed between smaller cities in a variety of ways within a complex relationship, as well as in the cooperation between big cities.

The construction of aversive facilities in the city which involves social issues such as the Nimby (Not in my back yard) phenomenon has found a solution in the cooperation between neighboring cities. Also, in Korea, effective cooperation on environmental, social and mutual issues with regards to critical infrastructure and necessary but aversive structures has been proven effective. In this study, the implications of city-to-city cooperation for the installation of aversive environmental infrastructure will be drawn out.

TABLE I: SELECTION OF CASES

\begin{tabular}{l|l|l}
\hline \hline \multicolumn{2}{c}{ Sharing Facility } & \multicolumn{1}{c}{ Sharing Method } \\
\hline $\begin{array}{l}\text { Co-construction of } \\
\text { Hwaseong city } \\
\text { comprehensive } \\
\text { funeral facility }\end{array}$ & funeral facility & $\begin{array}{l}\text { co-construction and } \\
\text { intercommunity }\end{array}$ \\
\hline $\begin{array}{l}\text { Intercommunity of } \\
\text { Chuncheon city and } \\
\text { Hongcheon city }\end{array}$ & $\begin{array}{l}\text { crematorium } \\
\text { manure facilities }\end{array}$ & $\begin{array}{l}\text { intercommunity } \\
\text { facilities exchange }\end{array}$ \\
\hline $\begin{array}{l}\text { Asan Resource } \\
\text { Recovery Facility }\end{array}$ & incinerator & sharing use \\
\hline $\begin{array}{l}\text { Dongbugwon } \\
\text { Greater Resource } \\
\text { Recovery Facility }\end{array}$ & incinerator & $\begin{array}{l}\text { co-construction and } \\
\text { intercommunity }\end{array}$ \\
\hline $\begin{array}{l}\text { Intercommunity of } \\
\text { Guro-gu, Seoul and } \\
\text { Gwangmyeong city }\end{array}$ & $\begin{array}{l}\text { Incinerators } \\
\text { sewage treatment plant }\end{array}$ & $\begin{array}{l}\text { facilities exchange } \\
\text { intercommunity }\end{array}$ \\
\hline \hline
\end{tabular}

\section{B. Methodology}

Environmental infrastructure installation in the context of 
inter-city cooperative methods regarding the installation of facilities seen as aversive has been investigated. These particular facilities in Korea were chosen based on their public image as aversive facilities and the city-to-city cooperation behind their construction. Local facilities such as funeral facility, incinerators, manure facilities, and sewage treatment plants were selected. First, the city-to-city methods used to use the facilities and their implications were drawn out. Second, the result of the city-to-city cooperation and its effect were investigated (see Table I).

\section{Status OF KoREA}

In Korea, complex issues associated with graves and their attendant funeral culture has emerged, such as graves encouraging land erosion, the landscaping of the funeral culture, site recognition, legal issues involving the environment and other a myriad of social and economic rights. Accordingly, the need for an environmentally friendly crematorium and ossuary setup was spread. And the "Burial and Graveyard, etc. ACT" was revised to the "Act on funeral services. etc.", making the local government responsible for the construction of funeral facilities [7]. Due to the costs of construction and the aversion of local residents about the burial facilities, however, neighboring cities began to "share" such facilities.

In addition, as available landfill decreases and groundwater contamination increases, the waste incineration policies are strengthened, meaning local governments have an increased need for resource recovery facilities. However, even though building resource recovery facilities in the city reduces the waste transport time, making the waste treatment process more efficient, the local aversion to them remains the biggest obstacle to that solution. Moreover, the poor financial situation of local government also increase the difficulty of building a new facility. Even though newer incinerators, unlike their older counterparts, have a minimal impact on the living environment while positively affecting efficiency and applying environmentally friendly technologies, the stereotypes based on the older models still persist and exert great influence. Livestock manure and sewage treatment facilities along with other resource recovery facilities are being shunned by locals in a similar fashion.

One can anticipate that facilities such as the above will engender disapproval and aversion on part of the public, especially in close proximity to a residential area. Nevertheless, by looking at the examples of successful urban communication and cooperation with regards to these issues, the implications of such will be drawn out and examined.

\section{CASE STUdY}

\section{A. Co-construction of Hwaseong Comprehensive Funeral Facilities}

Due to changes in national policy and public perception, the rate of cremation is increasing every year. However, in the current Gyeonggi area, crematoriums could not keep up with demand. Additionally, as the crematoriums limited the time of non local citizens and charged up to 20 times the normal price, local residents had complained of difficulties in using these facilities. To this, the nearby city of Hwaseong consulted with neighboring cities and, in May of 2013, announced that they were 'receiving applications for candidates to build a joint funeral facility'.

The 10 cities participating in the co-construction are Hwaseong, Bucheon, Gwacheon, Gunpo, Siheung, Anyang, Uiwang, Pyeongtaek, Ansan, Gwangmyeong and the like, all of which are adjacent to the city seonamgwon. Each municipality sought to address potential aversion to the proposed facility by campaigning with the theme of how a "state-of-the-art crematorium can be furnished with amenities and comfortable like a park", holding a number of guest lectures by experts and briefing sessions for local inhabitants.

In addition, in August 2010, swimming pools, sports centers and other such facilities were built near the resource recovery facility in the Hwaseong Bongdam area, causing nearby residents to recognize that these aversive facilities could lead to regional development. Eventually the residents in the crematorium candidates competitively supported their bid, and after 10 municipalities made their evaluations, maesongmyeon was selected in August 2013 as the final candidate.

After this joint decision, there was considerable expectation regarding economic development and job creation spurred by visitors to the facility on part of the residents. The joint funeral facility is scheduled for completion in 2018, with Hwaseong building special business accounts and operation regulations for this installation.

This particular case can be said to have successfully turned around the negative residential attitude towards what was traditionally aversive facilities. The fact that this attitude change came about primarily through the residents' expectation of economic improvement suggests that the change in social perception was tied to a corresponding economic value.

\section{B. Chuncheon, Hongcheon Joint-Use Facilities (Crematorium, Manure Facilities)}

As areas adjacent to each other, Chuncheon and Hongcheon formed a Partnership Development Council in March of 2008. The Council was to continually develop and promote issues requiring cooperation, one of which involved potentially co-constructing a joint use crematorium.

Though geographically large, Hongcheon only had a population of 70,000 and was dubious of the effectiveness of a facility with a low budget. Conflict with residents who opposed the building of a crematorium also contributed to this hesitation, during which the residents were forced to travel long distances and pay higher fees to use the neighboring funeral facilities. Chuncheon, on the other hand, had moved its old crematorium because of city development and was planning on building a new one. Though this spurred talks of co-construction between the two cities, talks stagnated due to opposition from residents in Chuncheon where the new crematorium was to be built. They disliked the presence of such aversive facilities in their area as well as the potential influx of outside visitors. To overcome this 
Chuncheon promoted presentations and discussions with the residents in order to persuade them of the necessity of crematory facilities, efforts from which finally bore fruit in August of 2009, when the residents finally gave their approval. In return, the local government promised residents their support in creating jobs, co-housing construction, Korean beef restaurants and other regional income creating efforts along with using $14 \%$ of the facility's income for village development. After receiving residential consent, both cities began the construction of the facility, establishing the Crematorium Joint Committee in May 2012, and signed a joint construction agreement in November. The Chuncheon City Crematorium opened in May 2014, and became known as the product of cooperation between Chuncheon and Hongcheon.

While the joint-use crematorium had smooth sailing, the two cities also discussed the joint use of the animal manure facilities, something of a dilemma to Chuncheon. Chuncheon originally had no such facilities, forcing them to stockpile livestock manure from their livestock farmers. The overabundance of manure was causing odor and hygiene problems, with a substantial amount being dumped into the river causing water pollution and odor to the discomfort of local residents. Chuncheon's own efforts to address this never solved the problem. Empowered by the cooperative success of the crematorium with Hongcheon, however, the manure handling practices Joint Council was established in February of 2013 and an agreement to jointly process manure was reached in August of 2013.

As a result of the cooperation between these cities, residents were able to ameliorate the issues caused by livestock manure, the local municipalities were able to resolve problems difficult to resolve alone, and save 2.5 billion won that would otherwise be spent on plant construction. Hongcheon residents were able to use the joint crematorium at an accessible price with ease, while the principality avoided spending about 11.2 billion won for crematorium construction and operation. Thus, the Chuncheon, Hongcheon cooperative practices sought to solve economic and environmental issues compounded by social phenomena faced by each city as a shared problem, resulting in environmental and economic benefits and proving to be a good example of social cooperation.

\section{Asan Resource Recovery Facility}

This is a case study involving Asan's resource recovery facility (which was losing money due to significant idling capacity) which was subsequently used jointly by Dangjin and Hongseong, two cities neighboring Asan. While normally in these cases the city with excess capacity limits the usage of its facility by neighboring cities, in this case Asan first approached the other two cities regarding joint usage of its resource recovery facility.

Asan's New City Development plan was initially based upon a projected 2016 population of 500,000 with a resource recovery facility commensurate to that population, able to process 200tons of material a day. In August 2005, when selecting the facility's site, the city offered various incentives and plans for environmental science parks in the area, along with pledging $10 \%$ of the facility's gross for the village development to form a consensus with the residents. In 2010 however, the Korea Land \& Housing Corporation (LH) significantly reduced the scale of their New Asan development plans, thereby significantly reducing the projected population in the area. Nevertheless, in May of 2011 the resource recovery facility was completed as initially planned, along with the environmental science parks and the other various facilities. Due to these changes, the resource recovery facility was only taking in about 120 tons/day, or about $60 \%$ of its total capacity, causing considerable economic loss to the city.

Hongseong, on the other hand, only had a small waste treatment facility in 2011 which by that time had deteriorated to the extent that it practically produced no energy. Though this facility cost Hongseon 1.2 billion won a year to operate, attempts to build a new one was met with opposition by the residents and difficulties in funding. Dangjin at the same time didn't even have such a facility and was forced to outsource its trash, spending 3.9 billion won a year in waste disposal costs.

Asan, struggling to efficiently use its resource recovery facility, suggested to these cities that they share usage of Asan's facility. So Asan signed a waste consignment processing agreement with Hongseon in November 2011 and again with Dangjin in June of 2013 increasing usage of Asan's resource recovery facilities up to $90 \%$ capacity. As a result, Asan's non-tax receipts increased by 3.1 billion won and usable steam scaled up with the increase in the incineration capacity usage. Hongseong saved 3 billion won a year in waste disposal, while Dangjin saved 4.5 billion won a year, all the while preventing the needless production of another government building. The city-to-city cooperation regarding Asan's resource recovery facilities in this case led to an increase in the energy recovery of resource recovery facilities, prevented unneeded government expenditure, and profited each city involved. This is a case study worthy of a second look, where city-to-city solution led to a remarkably economic success from the once economic problem.

\section{Dongbugwon Greater Resource Recovery Facility}

Before the current resource recovery facility in Dongbugwon, Icheon was built, Icheon had already attempted to build similar infrastructure twice. The first attempt was a failure from the beginning, with strong opposition from the target area and its neighbors as well as running afoul of several pertinent laws [8] regarding such facilities and the surrounding environs. Using this first attempt as a mirror, however, Icheon tried again, staying within the law and involving the locals with meetings and conferences in a bid to persuade them. Although this attempt also failed in large part due to continued opposition from the residents, ultimately it was the city itself which decided shut the project down. While promoting this project, Icheon was also negotiating with five cities/counties regarding their incinerators. As the five cities/counties confirmed the building of an incinerator in June 2003, Icheon quietly stopped planning out the second incinerator in July 2003 and completely canceled the entire project in January of 2004.

The dongbugwon wide resource recovery facility was jointly proposed and built by Icheon, Yeoju City, Guangzhou, 
Hanam, and Yangpyeong. Residential protests and budgeting issues which stonewalled Icheon's second incinerator project were overcome through the joint cooperation of these five cities/districts, while the success of the joint project could partly be attributed to Icheon's experience with previous failures. In addition, adjunct facilities built for the convenience of the residents provide pleasant and affordable conditions for locals.

Though the cooperative effort in building the Dongbugwon wide resource recovery facilities was encouraged by the central government (specifically the Ministry of Environment), analysis shows Icheon's experience with past failures was a primary factor in promoting the cooperation of the five cities. After experiencing two failures and knowing their causes, the city government turned to intercity cooperation in order to overcome those factors, such as the solitary nature of the project, lack of citizen participation, legal violations, financial difficulties and the like (see Table II). This example involving Icheon and its neighboring cities shows how it's better for cities to cooperate with each other in the building of public facilities rather than having each city build its own infrastructure. This promotes both efficiency in business and cooperation between regions, and discourages waste in governmental spending.

TABLE II: FAIL FACTORS OF ICHEON IN THE PAST

\begin{tabular}{|c|c|}
\hline Division & Contents \\
\hline $\begin{array}{l}\text { Fail factors of } \\
\text { facility installation }\end{array}$ & $\begin{array}{l}\text { - Sole plan of local government without citizen } \\
\text { - Lack of citizen participation } \\
\text { - Ordinance violations } \\
\text { - Financial difficulty of local government }\end{array}$ \\
\hline
\end{tabular}

\section{E. Guro-gu, Seoul Gwangmyeong, Joint Use of Facilities} (Resource Recovery Facilities, Sewage Treatment Plants)

Guro gu and Gwangmyeong were experiencing both individual and joint difficulties in various long term projects. Meanwhile Gwangmyeong's resource recovery facility had some idle capacity, leading to these two districts pushing a big environmental deal aimed towards joint usage of public facilities. The main idea was for Guro to use Gwangmyeong's idle capacity while Gwangmyeong used Guro's sewage treatment plants, which was the aim they pushed towards in a series of negotiations and meetings between Guro, Seoul, Gyeonggi-do, Guro-gu, and Gwangmyeong.

Beginning in March of 1998 over a course of 8 months, four meetings were held with Seoul, Gyunggido, Guro-gu, and Gwangmyeoung represented, with the 14th executive council of the metropolitan area held in May of 1999 which resulted in the publication of the joint use of facilities between Guro and Gwangmyeong. The integration and expansion process for Gwangmyeong's sewage treatment plant was agreed upon in November of 1999, while the joint usage for Guro's recovery plant was agreed upon in April of 2000. Though the process began in May of 2000, some citizens protested the processing of Guro's trash. In the process of persuading these residents, the district of Gwangmyeoung agreed to give 4 billion won to the residential support fund over three years. It was in July 2000 that the importation and processing of Guro's trash began.

With the joint usage of these facilities, Guro and Gwangmyeong were able to save money from preventing expenditure on unnecessary buildings and also avoided residential protests new facilities would have engendered. Additionally the expansion of their sewage treatment plants for Gwangmyeong has increased tax revenue while the joint committee for the resource recovery facilities has worked to minimize conflict with locals through meetings and conferences for the past 15 years. To find an agreement on the joint use of infrastructure there were continued consultations between Guro and Gwangmyeong, with the Greater Seoul and Gyeonggi Province, with the mediation of the Ministry of Environment, and various publicized meetings for these projects with the Metropolitan Council, all of which played an important part in the ultimate success of this deal.

This case shows how the intervention of the central government and metropolitan authorities can catalyze city-to-city cooperation. The cooperative effort of Guro and Gwangmyeong is a model example of the joint usage and cooperation, and the continuing production of economic/social/environmental value through the continued cooperation of these districts has strong implications for the idea of city-to-city cooperation.

\section{F. Comprehensive Analysis}

City-to-city cooperation regarding environmental infrastructure is expressed in the form of "sharing" facilities. The facilities found in the examples above include incinerators, manure treatment plants, and sewage treatment plants, etc., with the joint use of such meaning sharing, co-construction of new facilities and exchanging usage of each city's facilities. Due to the local population's natural aversion to such infrastructure and the Nimby phenomenon, the process of persuading residents is essentially mandatory. Agreements and regulations are pursued, and followed by the attempts to persuade residents using citizen meetings and conferences. These efforts must be made before a location is determined for positive citizen participation to occur [9].

TABLE III: COMPREHENSIVE ANALYSIS OF CASES

\begin{tabular}{|c|c|}
\hline Division & Contents \\
\hline Property Type & $\begin{array}{l}\text { - funeral facilities } \\
\text { - incinerators } \\
\text { - manure treatment plants } \\
\text { - sewage treatment plants }\end{array}$ \\
\hline Way of sharing & $\begin{array}{l}\text { - intercommunity } \\
\text { - co-foundation } \\
\text { - exchange utilization }\end{array}$ \\
\hline Process & $\begin{array}{l}\text { - With efforts to convince residents and secure } \\
\text { financing }\end{array}$ \\
\hline Results and Effects & $\begin{array}{l}\text { - curtailment of facility construction costs } \\
\text { - curtailment of administrative costs } \\
\text { - strengthen local relationship }\end{array}$ \\
\hline
\end{tabular}

Financial support from the government comes in the form of subsidies, with the majority of cost laid upon the city in which the infrastructure is to be constructed. Due to the heavy cost and light budgets, provincial governments find it advantageous to approach neighboring provinces and 
cooperate with them to build joint usage infrastructure. These joint efforts result in lower costs to build the facilities and persuade residents while encouraging intra and inter regional cooperation. Analysis shows the economic benefits from these facilities to the locals especially serve to strengthen the public's trust and pay societal dividends, leading in turn to regional solidarity and encouraging future cooperative projects (see Table III).

\section{CONCLUSION}

The cooperative process in building these aversive facilities stems from the economic demands involved in political/social/environmental costs the infrastructure requires and the local government's efforts to accommodate them. This environmental infrastructure is essential for the maintenance and creation of any city. Though modern technology used in these facilities makes pollution and odor free, public perception of this infrastructure remains a negative one. But through cooperation with neighboring cities, the immediate problem is solved and additional value is created while the city's quality of life rises.

In order to build a future of sustainable cities competitive globally, it is wiser to focus on win-win development instead of focusing on each individual city's growth. To build the foundational infrastructure necessary for city development, especially environmental infrastructure, requires a change in public perception which in turn requires significant governmental effort. Taking the results of this study into account, city-to-city cooperation shows great promise in dealing with the difficulties encountered while building or reconstructing needed environmental infrastructure.

\section{REFERENCES}

[1] D. Kim, "An urgent alternative for climate change: Green city," Green Monitor: Technology·Policy Review, 2014

[2] UN Habitat. (May 2001). City-to-City Cooperation. [Online]. Available: http://www.un.org/ga/istanbul+5/city-to-city.pdf

[3] CITYNET. (2012). C2C Introduction Leaflet. [Online]. Available: http://citynet-ap.org/?s=c2c\&amp; $=-810 \& y=-58$

[4] UN. (2014). Revision of World Urbanization Prospects. [Online]. Available:

http://www.un.org/en/development/desa/publications/2014-revision-w orld-urbanization-prospects.html

[5] Y. Jo, S. Sohn, and D. Kim, "Key indicators of the index for a green city," Urban Design, vol.14, no. 6, pp. 111-123, June 2013.

[6] Y. Kim, "Encouraging collaboration between the central government and local governments for the low-carbon society," Ph.D. dissertation, Dept. Public Administration, Kyonggi University, Korea, 2011.

[7] Act on funeral services. etc. Article 4 (Duties of State and Local Governments).

[8] Promotion of Installation of Waste Disposal Facilities and Assistance, etc. to Adjacent Areas Act Article 9 (Selection of Locations of Waste Disposal Facilities).
[9] C. Shin, "Cause and solution of NIMBY Conflicts," in Proc. the 2009 Winter Conference of the Korean Association for Local Government Studies, Feb. 2009, pp. 329-357.

[10] Research Institute for Gangwon, Policy Memo, no. 171, pp. 1-14, July 2012.

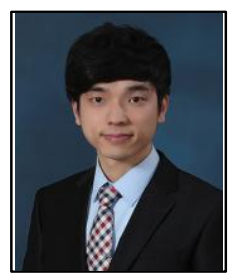

Injae Yu was born in Tokyo in June 1987. He is a student in master's course future city convergence engineering major at Sung Kyun Kwan University (SKKU) where he is a researcher of Smart Green City Lab. Injae has participated in some projects such as workplace and smart city, creative town, U-city plan as a researcher of Smart Green City Lab.

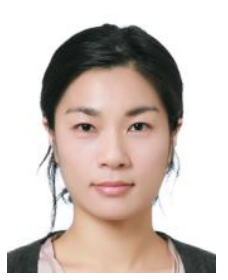

Yoojung Jo was born in Seoul in January 1982. She is a candidate for the Ph.D of future city convergence engineering major at Sung Kyun Kwan University (SKKU). She is a senior researcher of Smart Green City Lab in SKKU.

Yoojung received her master's degree in 2009. After graduating, she has studied as a researcher until now. She has conducted a study on algorithm for preventive maintenance of u-City infrastructure, index for a Green city, u-City district units, and etc.

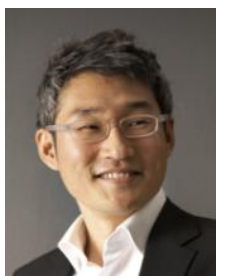

Saehyung Sohn was born in Seoul in 1969. He is a professor of architecture at Sung Kyun Kwan University (SKKU) and the UK Royal architect. After graduating from London AA School in 2000, he carried out a number of health-related projects, airport master plan and terminal design project as a senior designer on design core team of Ken Yang, a global green architect, in Llewelyn Davies Yeang.

After returning to Korea in 2008, as a design director at Geonwon Architectural firm he fullfilled a variety of projects including residential complex facilities, airports, business facilities, government offices and B1 Block of Songdo IBD for about two years.

Since then, he has carried out carbon reduction strategies and smart urban city and U-city plan projects and served as a member of U Smart Research Committee in Korea Urban Design Institute.

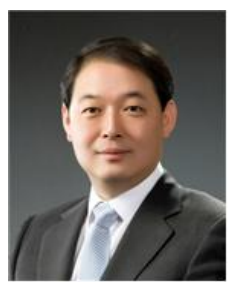

Donyun Kim was born in Seoul in 1963. He is a professor of urban design at Sung Kyun Kwan University (SKKU) where he is the director of Smart Green City Lab. He is currently a commissioner of the presidential committee on green growth and a vice president of urban design institute of Korea.

Donyun has been a chief planner of Seoul Digital Media City (DMC) since 1997. Currently he is also working with the Presidential Office of Korea to integrate the ideas of city-making industries and smart sustainable technologies into a paradigm of 'green growth', which have the potential to support the healthy and green urbanization of Asian and African countries. In addition, he has been involved in a national research project of establishing a strategy for a low-carbon city, as the chief of the research, which includes the improvement in related legal system and the development of green city index.

He holds a master degree of urban design at Pratt in New York and a Ph.D degree at Seoul National University in Korea. He has been a visiting professor and research affiliate of the city design and development group at MIT. In 2013, Dr. Kim was awarded a medal from national government of Korea for his distinguished academic and professional contribution. 